\title{
Identificação dos pontos críticos no sistema extrativista da mangaba (Hancornia speciosa Gomes) em Sergipe
}

\author{
Identification of critical points in the extrativist system of mangaba (Hancornia speciosa Gomes) \\ in Sergipe
}

\author{
Débora Moreira de Oliveira ${ }^{1}$ \\ Daniela Silva Cruz ${ }^{2}$ \\ Bruno Antônio Lemos de Freitas ${ }^{3}$ \\ Thaiane Natalle Moreira Lima ${ }^{4}$ \\ Laura Jane Gomes ${ }^{5}$
}

\section{Resumo}

A identificação dos pontos críticos é uma das etapas no processo de seleção dos indicadores de sustentabilidade. Para que os indicadores sejam eficazes é fundamental a participação dos atores envolvidos. $\mathrm{O}$ objetivo desta pesquisa foi identificar os pontos críticos do sistema extrativista da mangaba no estado de Sergipe, a fim de subsidiar a seleção de indicadores de sustentabilidade para o monitoramento da cadeia produtiva. Para isso, foi abordada a problemática do uso sustentável dos frutos da mangaba a partir da visão dos atores sociais vinculados a cinco Associações de Catadoras de Mangaba (ACMs) do estado de Sergipe. Os dados foram coletados por meio de oficinas com o uso de duas ferramentas de Diagnóstico Rural Participativo: Matriz F.O.F.A (Fortalezas, Oportunidades, Fraquezas e Ameaças) e Matriz de Priorização de Problemas. O diálogo estabelecido nas oficinas das diferentes ACMs permitiu identificar oito Fortalezas e seis Oportunidades, bem como Fraquezas e Ameaças, que, após serem listadas na Matriz de Priorização de Problemas, deram origem a 15 pontos críticos. Destes, três pontos críticos foram considerados prioritários: poucos compradores para produtos beneficiados; não possuir terras próprias para extrativismo; queimadas e desmatamento. $\mathrm{O}$ uso dessa metodologia permitiu selecionar pontos críticos condizentes com a realidade dos atores sociais das ACMs, de modo que serão essenciais à construção de indicadores de sustentabilidade que possam viabilizar o monitoramento da atividade no estado de Sergipe.

Palavras-chave: Mangabeira. Extrativismo. Sociobiodiversidade. Indicadores. Sustentabilidade.

\begin{abstract}
The identification of critical points is one of the steps in the process of selecting sustainability indicators. In order for the indicators to be effective, the participation of the actors involved is essential. The objective of this research was to identify the critical points of the mangaba extractive system in the state of Sergipe, in order to subsidize the selection of sustainability indicators to monitor

\footnotetext{
${ }^{1}$ Mestre em Desenvolvimento e Meio Ambiente (UFS). Doutoranda no Programa de Pós-Graduação em Desenvolvimento e Meio Ambiente da Universidade Federal de Sergipe (PRODEMA/SE). E-mail: d.oliveira.doc@gmail.com.

${ }^{2}$ Graduanda em Engenharia Florestal (UFS). E-mail: cruz.da.ni@ hotmail.com.

${ }^{3}$ Mestre em Agricultura e Biodiversidade (UFS). Doutorando no Programa de Pós-Graduação em Fitotecnia da Universidade Federal de Viçosa (UFV). E-mail: brunoalf@ hotmail.com.

${ }^{4}$ Mestre em Desenvolvimento e Meio Ambiente (UFS). E-mail: thaianenmlima@gmail.com.

${ }^{5}$ Doutora em Engenharia Agrícola (UNICAMP). Professora Associada do Departamento de Ciências Florestais (DCF) e do Programa de Pós-Graduação em Desenvolvimento e Meio Ambiente da Universidade Federal de Sergipe (PRODEMA/SE). E-mail: laurabuturi@gmail.com.
} 
the production chain. For this, the problem of the sustainable use of mangaba fruits was approached from the perspective of the social actors linked to five Associations of Catadoras de Mangaba (ACMs) of the state of Sergipe. Data were collected through workshops using two tools of Participatory Rural Diagnosis: S.W.O.T Matrix (Strengths, Weaknesses, Opportunities and Threats) and Prioritization of Problems Matrix. The dialogue established in the workshops of the different ACMs identified eight Strengths and six Opportunities, as well as Weaknesses and Threats, which, after being listed in the Prioritization of Problems Matrix, gave rise to 15 critical points. Of these, three critical points were considered as priority: few buyers for products benefited; not own land for extractive purposes; burning and deforestation. The use of this methodology allowed the selection of critical points consistent with the reality of the social actors of the ACMs, so that it will be essential to construct sustainability indicators that can enable the monitoring of the activity in the state of Sergipe.

Keywords: Mangabeira. Extractivism. Sociobiodiversity. Indicators. Sustainability.

\section{Introdução}

A exploração da biodiversidade vegetal por meio do extrativismo envolve comunidades rurais que realizam atividades diversas desde a coleta, beneficiamento e processamento dos produtos (HOMMA, 1982), configurando-se como atividade de elevada importância na vida de diversas populações tradicionais (BENATTI, 2000), que não apenas exploram, mas também manejam esses recursos (POSEY, 1987).

No Brasil, ainda existem centenas de produtos extrativos que, por não apresentarem maior peso à economia do país, são pouco estudados na área acadêmica (HOMMA, 2010), bem como não recebem proteção adequada por meio de políticas públicas. Esse déficit é um risco para muitas espécies, na medida em que o crescimento do mercado induz à "domesticação, destruição dos estoques, degradação ambiental, privatização da terra, substituição por alternativas econômicas e aparecimento de substitutos" (idem, p. 353).

A mangaba, fruto da mangabeira (Hancornia speciosa Gomes), é um produto extrativo de grande relevância para o país, constando inclusive nos relatórios anuais do Panorama do Extrativismo Vegetal e da Silvicultura (PEVS), publicação anual do Instituto Brasileiro de Geografia e Estatística (IBGE). A árvore ocorre nas cinco regiões do Brasil - excetuando-se os estados de Santa Catarina e Rio Grande do Sul (na região Sul do país), bem como Acre e Roraima (na região Norte do país) apresentando-se em seis variedades botânicas aceitas, que se diferenciam principalmente por diferenças morfológicas das folhas e flores (MOURA et al., 2008; KOCH et al., 2015).

Dados do PEVS apontam que, ao longo dos anos, o estado de Sergipe tem se mantido como o maior produtor de mangaba do país, alcançando uma produção de 353 toneladas no ano de 2014 (IBGE, 2014). O extrativismo do fruto da mangabeira é a principal fonte de renda para inúmeras famílias sergipanas e a comercialização se dá tanto diretamente para o consumidor quanto para 
grandes indústrias de polpa e de sorvetes no estado - dados de 2009 apontaram que a fruta, inclusive, chegou a ser responsável por 25\% de toda a produção de polpas no estado (EMDAGRO, 2009).

Contudo, apesar da importância socioeconômica da espécie para Sergipe, as áreas onde há ocorrência natural das mangabeiras estão sofrendo intensa pressão por parte do cultivo de monoculturas (como cana-de-açúcar, coqueiro e eucalipto), expansão imobiliária, avanço turístico e implantação ilegal de viveiros de camarão - o que diminui as áreas disponíveis para extrativismo e gera maior pressão de uso sobre as áreas remanescentes (SILVA JÚNIOR et al., 2011), deixando claro a urgência de estudos que conduzam a um planejamento ambiental que assegure a conservação e o uso sustentável da espécie.

Nesse contexto, para Gomes, Gomes e Jesus (2010), é imperativo que a prática do extrativismo esteja presente na formulação de políticas públicas locais inseridas no âmbito de um planejamento ambiental coerente que, segundo Santos (2004), necessita obter dados representativos da realidade que auxiliem na escolha de alternativas viáveis - ressaltando que, para além de obter um banco de dados imenso sobre o meio analisado, é primordial que sejam selecionadas informações objetivas, representativas e de fácil interpretação, sobretudo, apresentadas por meio da mais importante ferramenta do planejamento ambiental: os indicadores de sustentabilidade.

Mediante o exposto, o objetivo desta pesquisa foi identificar os pontos críticos do sistema extrativista da mangaba a partir da visão dos atores sociais vinculados às Associações de Catadoras de Mangaba (ACMs) do estado de Sergipe, a fim de subsidiar a seleção de indicadores de sustentabilidade para a cadeia produtiva do fruto no estado.

\section{Percurso metodológico}

O presente manuscrito estrutura-se em duas partes: 1) uma apresentação teórica acerca dos temas "uso sustentável de PFNM de base extrativista" e "importância socioeconômica do fruto da mangabeira (Hancornia speciosa Gomes) para Sergipe"; e 2) um estudo de caso envolvendo cinco ACMs do estado de Sergipe ${ }^{6}$, a fim de discutir, na percepção dos atores sociais extrativistas, os principais pontos críticos que trazem desafios ao alcance da sustentabilidade da atividade no estado.

A escolha do público para a seleção dos pontos críticos do sistema extrativista da mangaba se deu por meio de amostragem não probabilística intencional, que permite selecionar um subgrupo da população que é considerado representativo da realidade estudada, com base nas informações

\footnotetext{
${ }^{6}$ A pesquisa foi autorizada pelo Comitê de Ética em Pesquisa da Universidade Federal de Sergipe com o número CAAE 54635216.5.0000.5546, parecer número 1.488.492.
} 
disponíveis e através do julgamento do pesquisador, quando é necessário incluir um pequeno número de unidades na amostra (MARCONI; LAKATOS, 1996; MAROTTI et al., 2008).

Esse viés foi utilizado pelo fato de que não há levantamento oficial do número de extrativistas no estado de Sergipe, impossibilitando o cálculo amostral probabilístico, bem como pelo fato de que nem sempre estes atores sociais encontram-se atrelados a algum tipo de organização social (como o Movimento das Catadoras de Mangaba de Sergipe (MCMS), Associações de Catadoras de Mangaba (ACMs) ou Projetos de Assentamento de Reforma Agrária) - o que dificulta o agendamento de oficinas através do contato com líderes e representantes. Assim, para os fins desta pesquisa, optou-se por contatar comunidades extrativistas que possuem ACMs e/ou participam do MCMS.

Os contatos, via visitas in loco, foram feitos de acordo com informações prévias sobre as localidades e comunidades em que há extrativismo da mangaba no estado, obtidas no site oficial do $\mathrm{MCMS}^{7}$ e em estudos acadêmicos. Após contatar os líderes das comunidades encontradas, foram selecionadas cinco comunidades que se disseram disponíveis para participar da pesquisa, a saber: Associação de Catadoras de Mangaba do Povoado Manoel Dias (Ascamade); Associação de Catadoras de Mangaba do Povoado Ribuleirinha do Município de Estância (ACMRE); Associação das Catadoras de Mangaba de Indiaroba (Ascamai); Associação de Catadoras de Mangaba do Povoado Porteiras do Município de Japaratuba (ACMPJ); e Associação dos Catadores de Mangaba Renascer do Povoado Baixa Grande (ACMRBG).

Após o contato com os líderes das ACMs, foi agendada uma oficina para cada localidade, realizadas durante o segundo semestre de 2016 com a participação livre de todos os associados. Durante as oficinas foram utilizadas duas ferramentas de Diagnóstico Rápido Participativo (DRP) (VERDEJO, 2006), empregadas a fim de descrever o sistema (cadeia produtiva da mangaba) e elencar os seus pontos críticos, a saber: Matriz FOFA (Fortalezas, Oportunidades, Fragilidades e Ameaças) e Matriz de Priorização de Problemas.

A duas ferramentas foram construídas com o auxílio de material visual confeccionado pela equipe de pesquisadores, que anotavam as falas dos extrativistas tanto para a visualização coletiva quanto para o detalhamento posterior da pesquisa (Figura 1). Assim, a Matriz FOFA foi construída após ser solicitado aos participantes que listassem as fortalezas e fraquezas internas à cadeia produtiva da mangaba, bem como as oportunidades e ameaças externas. Por sua vez, as fraquezas e ameaças citadas foram listadas na Matriz de Priorização de Problemas como "pontos críticos" da cadeia produtiva, e cada participante escolheu três desses pontos críticos como os mais problemáticos para

\footnotetext{
${ }^{7}$ www.catadorasdemangaba.com.br
} 
o funcionamento adequado da cadeia produtiva, dando origem a uma hierarquia que permite compreender quais pontos críticos são considerados mais importantes pela comunidade.

Convém ressaltar que o detalhamento das diferentes etapas da cadeia produtiva do fruto da mangabeira foi previamente discutido na mesma oficina, através do auxílio de outras três ferramentas de DRP: Mapa da Comunidade, Calendário de Atividades e Fluxo de Comercialização. Porém, esses dados não serão discutidos no presente manuscrito.
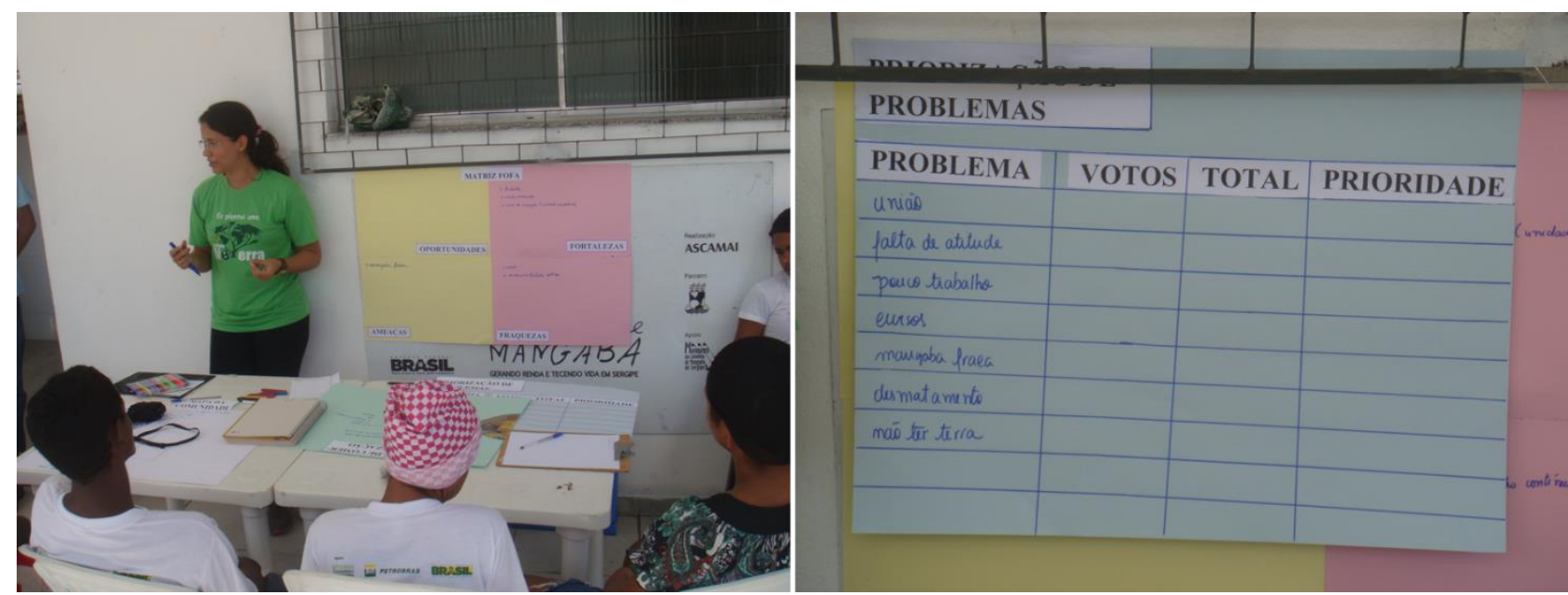

FIGURA 1 - USO DO MATERIAL DE AUXÍLIO VISUAL DURANTE OFICINA NA ASSOCIAÇÃO DOS CATADORES DE MANGABA DO POVOADO PORTEIRAS DO MUNICÍPIO DE JAPARATUBA FONTE: OLIVEIRA, 2016.

\section{Uso sustentável de Produtos Florestais não Madeireiros de base extrativista}

A fragmentação da cobertura vegetal original dos biomas brasileiros, especialmente a Mata Atlântica, tem levado a perdas na biodiversidade que, quando protegida, é provedora de serviços ambientais essenciais à sociedade (BRASIL, 2010; AEM, 2006). Entende-se que a redução da biodiversidade é um risco plurifacetado que envolve impactos nas esferas social, econômica, cultural, ambiental e científica (BRITO, 2006); e, neste contexto, destaca-se nos dias atuais a problemática do uso sustentável dos Produtos Florestais Não Madeireiros (PFNM) obtidos exclusivamente por meio do extrativismo, compreendidos, em sua maioria, como o único e/ou principal meio de subsistência de comunidades locais engajadas na obtenção desses recursos.

O extrativismo de recursos vegetais desempenhou e ainda desempenha alta importância na estrutura econômica e social do Brasil. Na década de 70, no contexto da expansão agropecuária adotada pelo Regime Militar, a perda de espaço de comunidades que realizavam o extrativismo do 
látex da seringueira - um Produto Florestal Não Madeireiro - $\mathrm{PFNM}^{8}$ - para os pecuaristas (ALMEIDA, 2004) foi o trampolim para o início das críticas aos desmatamentos e à política ambiental no país, e após a morte do líder dos seringueiros em 1998, o extrativismo de PFNM foi considerado como um novo paradigma para a conservação das áreas florestais no Brasil (HOMMA, 2012).

Nesse contexto, Homma (2012) alerta para a necessidade de uma visão que englobe as diversas facetas da sustentabilidade do extrativismo, visto que a sustentabilidade do ponto de vista biológico não garante que haverá sustentabilidade econômica e vice-versa. Assim, para o autor, é "falsa a concepção de considerar todo produto não madeireiro como sustentável” (idem, 2012, p. 168). Portanto, para explorar os PFNM de forma sustentável é imperativo que a prática esteja presente na formulação de políticas públicas locais, de modo a serem contemplados os fatores culturais, sociais, econômicos, ambientais e tecnológicos relacionados à atividade, visto que, juntos, geram impactos locais significativos (GOMES; GOMES; JESUS, 2010).

May (1991) aponta que alguns riscos estão associados ao mercado de comercialização de PFNM de base extrativista, a saber: 1) que a demanda pelos produtos pode induzir à seleção de culturas que possuam maior valor ou tenham crescimento mais acelerado; e que 2) se novos mercados são capturados por grandes comerciantes há a possibilidade de que as estratégias inovadoras de marketing possam colocar as indústrias em vantagem sobre os extrativistas. Assim, o autor questiona: a expansão dos mercados para os PFNM é uma opção sustentável para as comunidades extrativistas?

Por sua vez, Homma (2012) afirma que o extrativismo de PFNM caracteriza-se no contexto geral por uma fase de início seguida de rápida expansão, e, posteriormente, culminando em uma fase de estagnação e posterior declínio, tanto em relação ao tempo como à área espacial.

Portanto, entende-se que ao avaliar a sustentabilidade da exploração de determinado PFNM, é necessário um olhar sistêmico, pois os aspectos envolvidos fazem parte daqueles que, segundo Van Bellen (2005), compõem as dimensões do desenvolvimento sustentável: perspectivas econômica, social, ambiental, geográfica e cultural. A partir da década de 70, no contexto da agenda ambiental e da difusão do conceito de desenvolvimento sustentável, foram ampliados os esforços no sentido de desenvolver novos instrumentos capazes de mensurar o progresso/desenvolvimento rumo à sustentabilidade e, hoje, a ferramenta "indicadores de sustentabilidade" é frequentemente empregada

\footnotetext{
${ }^{8}$ Os PFNM são "os produtos vegetais que não a madeira e a lenha, oriundos de formações vegetais naturais ou manejadas" (SOLDATI; ALBUQUERQUE, 2010, p. 19), incluindo folhas, cascas, óleos, flores, tinturas, resinas, tubérculos, gomas, fibras, sementes e frutos, os quais são possibilidades ao ecodesenvolvimento e elevação de renda às populações extrativistas (CAVALCANTE, 2011).
} 
nas fases de decisão, implementação e avaliação de políticas públicas (GUIMARÃES; FEICHAS, 2009).

É imprescindível que os indicadores de sustentabilidade selecionados sejam compreendidos pelos atores sociais envolvidos no contexto analisado, a fim de despertarem o interesse da comunidade e nortearem as decisões que serão tomadas pelos grupos gestores (SANTOS, 2004), caminhando para uma situação ideal dentro do processo de planejamento, em que o grupo de atores sociais seja "ativo, tenha autocrítica, capacidade de entender os produtos técnicos, de estabelecer consenso, de elaborar estratégias e de resolver [...] a maior parte dos problemas que se apresentam" (SANTOS, 2004, p. 160). Porém, o que se verifica na prática é que a maioria dos estudos que envolvem indicadores de sustentabilidade ainda preconiza a seleção apenas por meio da revisão de literatura e as percepções oriundas do pesquisador/gestor local.

Dentre as ferramentas para seleção de indicadores e mensuração da sustentabilidade destacase o MESMIS - Marco para la Evaluación de Sistemas de Manejo de recursos naturales incorporando Indicadores de Sustentabilidad, desenvolvido no México por uma equipe interdisciplinar com representantes de várias instituições como uma tentativa de traduzir os princípios gerais da sustentabilidade em definições operacionais e indicadores e práticas no contexto dos sistemas de gestão de recursos naturais no campo (LÓPEZ-RIDAURA; MASERA; ASTIER, 2002).

O método MESMIS parte da definição do sistema de manejo a ter a sustentabilidade mensurada para a análise de sete atributos de sustentabilidade: produtividade, resiliência, confiabilidade, estabilidade, autogestão, equidade e adaptabilidade. A partir daí, segue-se uma hierarquia de etapas em que são delimitadas as Fortalezas e Debilidades do sistema em estudo, para, então, selecionar os Pontos Críticos do sistema, que darão origem à indicadores que levem em conta os aspectos sociais, ambientais e econômicos (MASERA et al., 2008).

Como exemplo de estudo da sustentabilidade do extrativismo de PFNM, encontra-se o estudo de Gomes e Silva-Mann (2013), que selecionaram indicadores de sustentabilidade para o extrativismo dos frutos da aroeira (Schinus terebinthifolius Raddi.) no território do Baixo São Francisco, utilizando o MESMIS. Após a seleção de 17 indicadores, os autores constaram que 14 (82,3\%) encontravam-se abaixo dos parâmetros desejáveis para se alcançar a sustentabilidade e, portanto, refletem a urgência da busca por estratégias para consolidar uma gestão florestal ampla para a espécie, incorporando ações de manejo sustentável, restauração florestal, domesticação, apoio à organização de produtores em cooperativas a fim de viabilizar produtos com maior valor agregado.

Nota-se que no referido estudo não foi realizado em nível local, municipal ou estadual, por compreender que a gestão do recurso em questão extrapola os limites político administrativos, aproximando-se na ideia de "território", atrelada atualmente à discussão acerca dos territórios dos 
povos e comunidades tradicionais ${ }^{9}$, que por serem grupos que estabelecem relações intrínsecas com as terras ocupadas tradicionalmente e seus recursos naturais "fazem com que esses lugares sejam mais do que terras, ou simples bens econômicos. Eles assumem a qualificação de território” (MPMG, 2014, p. 12).

No Brasil, a Política Nacional de Desenvolvimento Sustentável dos Povos e Comunidades Tradicionais (PNPCT) (BRASIL, 2007) busca ferramentas para consolidar os direitos dos povos e comunidades tradicionais, assegurando, por exemplo, a criação de Reservas Extrativistas - Resex, modalidade do Sistema Nacional de Unidades de Conservação - Snuc (BRASIL, 2000). Sobre a relação entre os territórios e as Resex, Leiva e Freitas (2010, p. 10) afirmam que:

Os territórios dos povos tradicionais se fundamentam em séculos de ocupação efetiva, o que fornece um peso histórico às suas reivindicações territoriais. Estas reivindicações estão associadas ao reconhecimento formal, por parte do Estado, das áreas de ocupação e uso por estas populações, as quais não são necessariamente terras, podendo ser trechos de rios ou áreas marinhas. Por fim, é salutar que se evidencie a relação carnal entre os territórios e as populações tradicionais como mecanismo contratual de uma política de cunho socioecológico. Trata-se de uma forma diferenciada de planejar políticas públicas de transferência de direitos de propriedade a grupos sociais que necessitam da natureza como base material para realizarem suas práticas culturais. As Reservas Extrativistas são um exemplo que expressa esse tipo de contrato social, onde temos pelo lado das populações locais, $o$ território e, pelo lado do Estado, como coletividade, a conservação da natureza, o bem-estar do seu povo e a contensão do êxodo para as cidades.

A Organização das Nações Unidas para a Agricultura e Alimentação - FAO também reconhece a importância da implementação de políticas públicas para a gestão de recursos naturais por meio da noção de territórios, por meio de um projeto denominado "Plataforma de Territórios Inteligentes", que visa proporcionar um espaço de conteúdo e intercâmbio de conhecimentos e experiências sobre o modelo de desenvolvimento territorial na América Latina e no Caribe e da União Europeia. A plataforma, inclusive, disponibiliza um conjunto de 30 indicadores para medir a sustentabilidade de territórios nas esferas econômica, social e ambiental, independentemente da sua dimensão administrativa (comunidade, município, departamento, região ou país) (FAO, 2017).

\footnotetext{
${ }^{9}$ Povos e comunidades tradicionais são "grupos culturalmente diferenciados e que se reconhecem como tais, que possuem formas próprias de organização social, que ocupam e usam territórios e recursos naturais como condição para sua reprodução cultural, social, religiosa, ancestral e econômica, utilizando conhecimentos, inovações e práticas gerados e transmitidos pela tradição" (BRASIL, 2007).
} 


\section{Importância socioeconômica e cultural da mangabeira para o estado de Sergipe}

De porte arbóreo, exemplares da mangabeira (H. speciosa) são encontrados espontaneamente nos tabuleiros arenosos e nos cerrados do Brasil, com até 10 metros de altura, tolerando bem solos ácidos e pobres e estresse hídrico (LIMA, 2010; GOMES, 2012). Destaca-se pelo fruto, que é uma drupa elipsoide de até $6 \mathrm{~cm}$, com coloração amarela estriada de vermelho. A polpa é branca, acidulada, delicada, perfumada e considerada por muitos como saborosa, sendo excelente para sorvetes, refrescos, compotas, doces, licores, dentre outros (GOMES, 2012).

Os usos associados à espécie estão relacionados principalmente à alimentação humana, através do consumo do fruto in natura ou após beneficiamento (geleias, polpas, doces, bolos, licores), ambas as opções bem aceitas no mercado. No entanto, outros usos menos evidentes podem ser empregados, tal qual o combustível, visto que a madeira pode ser utilizada como lenha de uso doméstico, bem como o uso medicinal da casca, folhas e raízes (LIMA, 2010; GOMES, 2012).

O extrativismo da mangaba no Brasil é relatado em escritos da época da colonização do país por diversos viajantes, exploradores e escritores, principalmente no estado da Bahia e em Pernambuco (SILVA JÚNIOR; MOTA; SCHMITZ, 2011). Os estados do Rio Grande do Norte e Sergipe se destacam sob a ótica dos conhecimentos, usos e aproveitamentos dos frutos pelas populações locais. Em Sergipe, desde a década de 60 há registros de tentativas de cultivo sob responsabilidade do antigo órgão Instituto Brasileiro de Desenvolvimento Florestal (IBDF), quando boletins técnicos nomearam a espécie como "Rainha dos Tabuleiros" (SILVA JÚNIOR et al., 2011).

Devido à pressão imobiliária nas capitais nordestinas e cidades turísticas, como Porto Seguro - BA, Barra de São Miguel - AL e Tamandaré - PE, houve uma diminuição da produção de mangaba regional. A produção no estado da Paraíba, por exemplo, deixou de constar nos registros do IBGE por sete anos (1998 a 2004). Em comparação aos demais estados do Nordeste, a queda da produção foi mais lenta em Sergipe, contudo, com a inauguração da rodovia litorânea Linha Verde na década de 90 e o consequente investimento em infraestrutura hoteleira, a paisagem tem sido rapidamente transformada (SILVA JÚNIOR; MOTA; SCHMITZ, 2011).

Em Sergipe, o bioma Mata Atlântica e seus ecossistemas associados onde ocorrem as populações naturais de mangabeiras ocupa aproximadamente 101.241,48 hectares, divididos em fitofisionomias de mata (76.124,71 ha), manguezal (23.012 ha), restinga (1.813,07 ha) e área natural não florestada (290,74 ha) (JESUS; GAMA; FERNANDES, 2014). Em relação às áreas do bioma em que ocorrem as populações naturais de mangabeiras, Silva Júnior e colaboradores (2011) afirmam que perda dessas áreas pela destinação a outros usos do solo têm resultado na formação de populações remanescentes de mangabeiras concentradas em áreas "pequenas, densas, altamente manejadas e com 
depauperação quase total da biodiversidade [...] provocando profundas alterações na disponibilidade e uso das plantas pelas catadoras de mangaba" (idem, p. 89).

Umas das alternativas apontadas como solução para pressão de uso gerada com base extrativista é a domesticação de espécies nativas, no entanto, a prática da silvicultura não é simples, e, segundo Valverde e colaboradores (2012, p. 12), "a ciência florestal brasileira tem encontrado dificuldades na domesticação das espécies nativas para o plantio em larga escala”, ainda que o país possua uma das maiores riquezas em termos de biodiversidade. Nesse contexto, os autores destacam que a consolidação da silvicultura brasileira depende da busca por um novo paradigma que resulte em mudanças substanciais apoiadas e fomentadas por distintos segmentos, inclusive e principalmente, o poder público.

$\mathrm{Na}$ década de 90, foram implantadas quatro unidades experimentais de plantio no estado de Sergipe, nas cidades de Itaporanga D'Ajuda, Estância, Neópolis e Santo Amaro das Brotas - como resultado de uma pesquisa conduzida pela Embrapa Tabuleiros Costeiros e a Emdagro, sob a responsabilidade de um pesquisador (FOLHA DE SÃO PAULO, 1995). No final da década seguinte, segundo o pesquisador, havia 300 hectares plantados da cultura no estado, e uma família que adotasse o plantio em apenas um hectare de terra (cerca de 200 unidades de mangabeiras) poderia obter até R\$ 10.000,00 de renda ao ano, após os cinco primeiros anos iniciais de estabelecimento da cultura; em contrapartida, no regime do extrativismo, a renda gira em torno de R \$1.500,00 (EMDAGRO, 2009).

Porém, a maior parte da mangaba oriunda do estado é de origem do extrativismo em áreas não cultivadas (LEDERMAN; BEZERRA, 2006). Segundo levantamento realizado no estado em 2009 (PEREIRA et al., 2009), que deu origem ao Mapa do Extrativismo da Mangaba em Sergipe (PEREIRA et al., 2010), a atividade de extrativismo da mangaba se dá ao longo de 12 municípios: Aracaju, Barra dos Coqueiros, Estância, Indiaroba, Itaporanga D’Ajuda, Japaratuba, Japoatã, Pacatuba, Pirambu, Santa Luzia do Itanhy, Santo Amaro das Brotas e São Cristóvão. Segundo os pesquisadores, a soma das áreas onde ocorria o extrativismo nesses municípios à época da pesquisa correspondia a 38.921 hectares (em 49\% dessa área é permitida a coleta dos frutos, em $12 \%$ é proibida a entrada, em $17 \%$ a zona é conflituosa e em apenas $16 \%$ as áreas são dos próprios extrativistas), com a participação de 64 comunidades e 1628 famílias.

Reconhecendo o significado cultural e econômico da espécie para o estado, bem como que ela se encontrava em vias de extinção, foi promulgado o Decreto Estadual n ${ }^{\circ} 12.723$, em 20 de janeiro de 1992, que instituiu a mangabeira como símbolo do estado de Sergipe (SERGIPE, 1992). Segundo Mota et al. (2011), a população que faz a coleta dos frutos no estado é predominantemente de mulheres negras que praticam uma diversidade de atividades para a subsistência e aquisição de renda (extrativismo animal e vegetal, agricultura familiar, artesanato). 
A memória oral sergipana relata que há muitas décadas populações negras ocuparam áreas de restinga e tabuleiros no estado, desenvolvendo uma relação intensa com os recursos naturais, então com condição de acesso facilitada. Contudo, com o passar dos anos, estabeleceu-se uma expropriação desses atores sociais, motivada pela intensificação do uso agrícola, expansão do turismo e outras atividades, confinando as populações a faixas estreitas e comprometendo o acesso ao território (MOTA et al., 2011).

Atualmente, um grupo de mulheres oriundo desse contexto histórico se autorreconhecem como "catadoras de mangaba", e após processo de mobilização social mediante auxílio de pesquisadores e lideranças das quebradeiras de coco-babaçu do Maranhão, criaram em 2007 o Movimento das Catadoras de Mangaba de Sergipe - MCMS, fruto do I Encontro das Catadoras de Mangaba de Sergipe (SCHMITZ et al., 2011). Alguns anos depois, a importância sociocultural desses atores sociais foi reconhecida na Lei Estadual $n^{\circ} 7.082$, de 16 de dezembro de 2010, quando reconhece as catadoras de mangaba como grupo culturalmente diferenciado e que, portanto, carecem de ser "protegidas segundo as suas formas próprias de organização social, seus territórios e recursos naturais, indispensáveis para a garantia de sua reprodução física, cultural, social, religiosa e econômica" (SERGIPE, 2010, Art. $1^{\circ}$ ).

Nesse contexto de mobilização social e luta por reconhecimento, foi criada a Associação das Catadoras de Mangaba e Indiaroba (Ascamai), que realizou em parceria com a Universidade Federal de Sergipe e apoio do Movimento das Catadoras de Mangaba de Sergipe o projeto "Catadoras de Mangaba: gerando renda e tecendo vida em Sergipe", que atuou entre os anos 2011 e 2015 através do patrocínio do Programa Petrobras Desenvolvimento \& Cidadania. Esse projeto teve, dentre suas ações, destaque para a criação de outras cinco Associações de Catadoras de Mangaba - ACMs, bem como a construção e entrega de quatro Unidades de Beneficiamento e Processamento de Frutas Tropicais e a criação da Cooperativa de Economia Solidária de Mulheres Extrativistas de Sergipe (Coopmese).

\section{Seleção dos pontos críticos no sistema extrativista da mangaba}

\section{Limitações nas oficinas}

Durante as cinco reuniões/oficinas houve a participação de 33 catadoras de mangaba, número relativamente baixo quando comparado à totalidade das famílias extrativistas no estado de Sergipe. Isso pode ser explicado por dois motivos: 1) As oficinas foram realizadas nas sedes das ACMs e após questionamento, os pesquisadores foram informados de que algumas vezes os extrativistas não 
associados não têm uma boa relação com as ACMs; 2) Os extrativistas presentes informaram que muitos associados não estão mais participando ativamente das associações de catadoras de mangaba, por motivos diversos.

Contudo, mesmo com tais limitações, entende-se que a seleção dos pontos críticos fidedignos à realidade local não será prejudicada, visto que os atores sociais presentes estão ativos na representação social que busca a manutenção do extrativismo da mangaba no estado de Sergipe e, portanto, conhecem a realidade pela vivência cotidiana.

\section{Fortalezas e oportunidades}

Notou-se, no geral, uma maior dificuldade em listar as fortalezas e oportunidades do que as fraquezas e ameaças. Enquanto as primeiras foram ditas por poucas participantes durante as oficinas, e com pouco apoio das demais, as últimas, quando ditas, obtiveram concordância e comentários tecidos por outras participantes, enriquecendo as discussões acerca dos temas. Acredita-se que isso tenha ocorrido pelo fato de que, ainda que haja fortalezas e oportunidades, na conjuntura atual da pesquisa estas se encontram ameaçadas por diversos fatores, conforme foi relatado durante as oficinas e será detalhado e discutido a seguir.

As seguintes FORTALEZAS para a cadeia produtiva da mangaba no estado de Sergipe foram citadas, agregando-se os dados das cinco oficinas realizadas: o trabalho (em si), a quantidade de mangaba, a organização em associações e a amizade entre os participantes, a infraestrutura adquirida com o projeto "Catadoras de Mangaba", venda nas feiras livres, terrenos para a coleta dos frutos e a localização turística das comunidades (Quadro 1).

QUADRO 1 - FORTALEZAS DA CADEIA PRODUTIVA DA MANGABA NO ESTADO DE SERGIPE, NA PERCEPÇÃO DAS ASSOCIAÇÕES DE CATADORAS DE MANGABA PARTICIPANTES DA PESQUISA

\begin{tabular}{|l|l|}
\hline \multicolumn{1}{|c|}{ FORTALEZA } & ASSOCIAÇÕES QUE CITARAM \\
\hline Trabalho (em si) & Ascamade, ACMPJ \\
\hline Quantidade de mangaba & Ascamade, ACMRE \\
\hline Organização em associações & ACMRBG, Ascamai, ACMRE \\
\hline Amizade nas associações & Ascamai, ACMPJ \\
\hline Infraestrutura adquirida no Projeto “Catadoras de Mangaba” & Ascamade, ACMPJ \\
\hline Localização turística & Ascamai \\
\hline Venda do fruto & ACMRBG, ACMRE \\
\hline Terrenos para a coleta dos frutos & ACMRE \\
\hline
\end{tabular}

FONTE: OLIVEIRA, 2016. 
Com relação ao trabalho, isto é, à cata da mangaba propriamente dita, as catadoras de mangaba participantes das oficinas relataram se identificar desde crianças com a atividade, sendo ensinadas pelos pais ou por parentes próximos e vizinhos. Para elas, os "verdadeiros catadores de mangaba" observam determinadas práticas durante a coleta a fim de que a produção das árvores se mantenha de forma sadia, por exemplo, através da utilização de ganchos para não necessitar subir nas árvores, da limpeza da área abaixo da copa, do cuidado para não quebrar galhos e retirar frutos verdes, bem como ao beneficiamento inicial dos frutos, separando após lavagem em água corrente por tamanho e grau de amadurecimento (Figura 2).
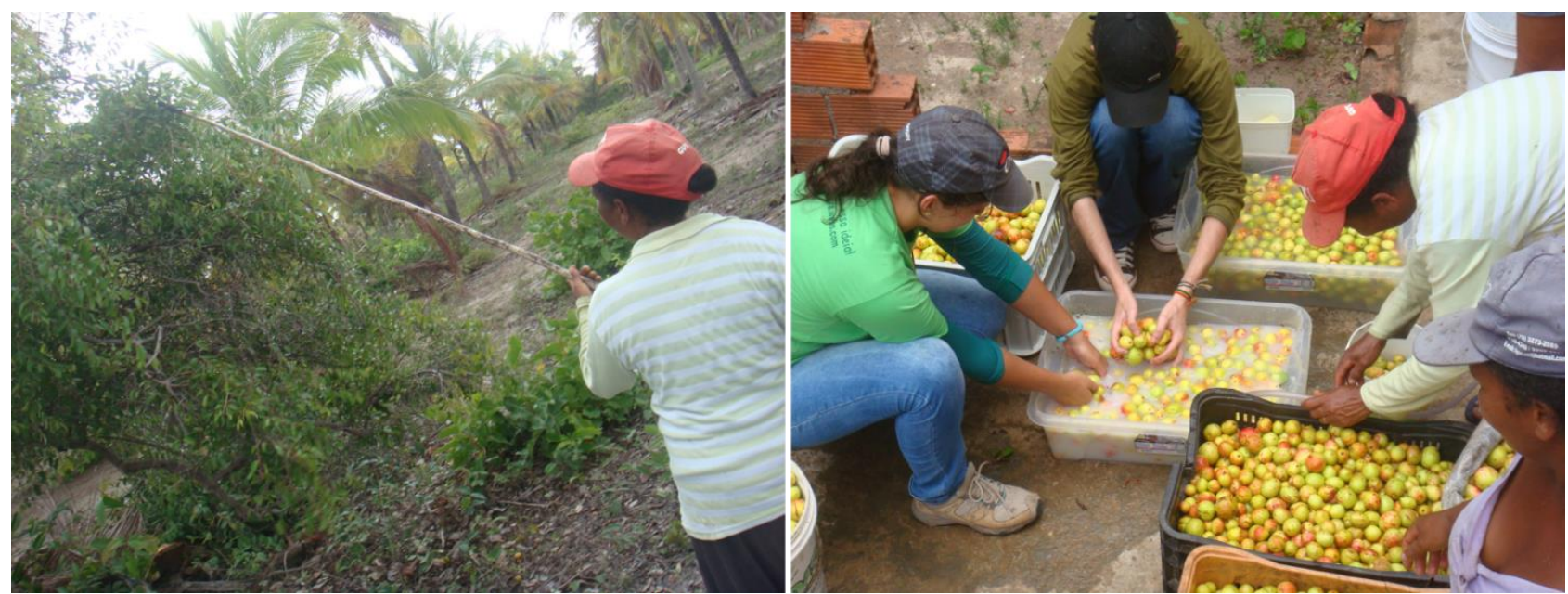

FIGURA 2 - COLETA DA MANGABA UTILIZANDO GANCHO E LAVAGEM DOS FRUTOS, JUNTO A EXTRATIVISTAS DO POVOADO BAIXA GRANDE

FONTE: OLIVEIRA, 2016.

A valorização do extrativismo da mangaba fica evidente em falas como "a mangaba é minha vida", "eu não teria nada sem a mangaba", "tudo que eu tenho vem da mangaba", ditas constantemente durante as oficinas. Os participantes das cinco comunidades ainda relataram o extrativismo de outros frutos (cambuí, araçá, manga, caju) e de recursos pesqueiros (peixes, mariscos, crustáceos), que são vendidos in natura ou processados (para as frutas, fabricação de doces, compotas etc.; para os recursos pesqueiros, extração de conchas, carapaças etc.).

As entrevistadas das comunidades de Porteiras (Japaratuba) e Baixa Grande (Pirambu) também incluíram na categoria "trabalho" os produtos oriundos de plantios em "roças", dentre os quais se destacam o amendoim, feijão, milho, macaxeira e batata-doce. Ressalta-se que, além da venda dos frutos da mangaba, que foi incluída como uma fortaleza por duas ACMs que afirmaram 
que o fruto "vende bem" (e demais produtos em feiras regionais e, no caso da mangaba, tanto em feiras quanto a atravessadores, turistas e às próprias Unidades de Beneficiamento).

Além da venda, essas atividades denominadas como "trabalho" também estão diretamente ligadas à subsistência familiar, visto que as cinco comunidades participantes até o momento relataram que tanto os frutos quanto os recursos pesqueiros e as culturas oriundas da agricultura familiar são utilizados diretamente na alimentação doméstica, incluindo a mangaba. Corroborando com Alegretti (2009), que afirma que na economia extrativista o extrativismo está associado à outras atividades como a agricultura de subsistência e à criação de animais de pequeno porte, podendo ser (como no caso do extrativismo da mangaba), em muitos casos, a atividade predominante. Assim, muitos autores têm substituído o termo "extrativista" por "agroextrativista", o que, segundo Silva e Miguel (2014), indica um possível reconhecimento de que o extrativismo é uma prática associada a outras atividades agrícolas e não agrícolas.

Apesar da indicação dessa fortaleza, as catadoras externaram sua preocupação com o fato de que o trabalho com o fruto da mangaba encontra-se ameaçado pela redução das áreas nativas de mangabeiras e pelo "cercamento" de áreas que antes possuíam acesso livre (ver o tópico Fraquezas e ameaças), bem como pelo crescente número de catadores que não conhecem as práticas adequadas de cuidado com as mangabeiras, que denominaremos aqui como "extrativistas ocasionais", cujas características, segundos os entrevistados, é de não conhecer as maneiras corretas de coletar o fruto, causando a quebra de galhos e a queda de frutos verdes.

A quantidade de mangaba foi indicada como uma Fortaleza, pois, segundo as participantes, ainda há uma grande quantidade de mangaba nos meses de safra. Contudo, logo em seguida à indicação da fortaleza era ressaltado que estavam notando uma diferença na quantidade de frutos nos últimos anos, fato atribuído por elas à pouca chuva (segundo elas, as plantas não têm água suficiente para produzir os frutos) ou muita chuva (segundo elas, se a chuva vier quando as flores ainda estão nas árvores ou os frutos estão jovens, a produção diminui pela queda tanto de flores quanto de frutos devido à força da água), bem como pelo desmatamento e queimada de áreas de mangaba e pelo maior número de "catadores ocasionais" nos últimos anos, segundo elas, motivados pelo fato de notarem que a venda da mangaba traz recursos financeiros para a família.

A organização em associações e a amizade entre os participantes foram também indicadas como fortalezas pois, segundo as catadoras, isso fortaleceu a união das mulheres extrativistas em suas respectivas comunidades, tornando mais efetiva a busca por direitos do grupo, bem como abrindo novas oportunidades de trabalho e geração de renda, por meio da infraestrutura implantada pelo projeto "Catadoras de Mangaba”, isto é, as Unidades de Beneficiamento (Figura 3). Porém, assim como nas demais fortalezas, logo em seguida foi citado que as associações muitas vezes não são bem 
vistas por outros catadores de mangaba, devido a julgamentos infundados dos extrativistas não participantes do projeto, bem como que há poucos compradores para os produtos beneficiados (ver o tópico fraquezas e ameaças).

Assim, durante os diálogos estabelecidos nas oficinas foi possível perceber que os atores sociais extrativistas estão "divididos" com relação àqueles que estão ou não filiados às associações de catadoras de mangaba e, consequentemente, ao MCMS e ao projeto "Catadoras de Mangaba: gerando renda e tecendo vida em Sergipe”. Na oficina do povoado Ribuleirinha (Estância), foi relatado que as catadoras não associadas preferem vender a mangaba até mesmo a preços inferiores para os atravessadores do que vender para a associação, e que, apenas em último caso (quando não conseguem vender o fruto na porta de casa, na feira ou para atravessadores) trazem os frutos para a associação - isso porque acreditam que as associadas recebem salário fixo para continuar a manter as Unidades de Beneficiamento funcionando. No povoado Porteiras (Japaratuba) foi relatada outra situação semelhante, em que as catadoras não associadas colocam altos preços no quilo do fruto por acreditarem que as associações têm muito dinheiro devido ao patrocínio do projeto pela Petrobrás.

A localização turística foi relatada pelos extrativistas da comunidade do Povoado Pontal, localizado no município de Indiaroba, litoral sul do estado de Sergipe. Esse povoado encontra-se às margens do Rio Real, que faz divisa entre os litorais de Sergipe e Bahia - local de destaque pela beleza natural, o que atrai turistas principalmente nos períodos de férias escolares e feriados nacionais. Além da Unidade de Beneficiamento da associação, os extrativistas mantêm um ponto de venda dos produtos em um estante localizado na residência de uma das associadas, que fica em frente ao local onde saem os barcos para Mangue Seco, povoado de atrativo turístico pois foi cenário para a gravação da novela e do filme "Tieta", baseados na obra do autor Jorge Amado.

Apenas as extrativistas do povoado Ribuleirinha afirmaram que a posse de terrenos para a coleta dos frutos é uma fortaleza, visto que nessa comunidade a maioria das associadas possui terra própria ou de parente onde é realizada a exploração do fruto. Contudo, essa é uma exceção, e, por conseguinte, o contrário foi apontado como uma fraqueza nas demais comunidades (ver tópico Fraquezas e ameaças).

Interessante destacar que, para as OPORTUNIDADES, foram citados apenas pontos relacionados aos produtos beneficiados, visto que nas ACMs participantes há unidades de beneficiamento do fruto, a saber: Inserção na concorrência para provimento de merenda escolar; Parceria com a Companhia Nacional de Abastecimento (Conab) e o Programa de Aquisição de Alimentos (PAA); Participação do Programa Nacional de Fortalecimento da Agricultura Familiar (Pronaf) mulher, obter Declaração de Aptidão ao Pronaf (DAP) das associações, viagens e eventos para divulgação dos produtos (Quadro 2). 
QUADRO 2 - OPORTUNIDADES DA CADEIA PRODUTIVA DA MANGABA NO ESTADO DE SERGIPE, NA PERCEPÇÃO DAS ASSOCIAÇÕES DE CATADORAS DE MANGABA PARTICIPANTES DA PESQUISA

\begin{tabular}{|l|l|}
\hline \multicolumn{1}{|c|}{ Oportunidade } & \multicolumn{1}{c|}{ Associações que citaram } \\
\hline Inserção na concorrência para provimento de merenda escolar & $\begin{array}{l}\text { Ascamade, Ascamai, ACMRE, } \\
\text { ACMPJ }\end{array}$ \\
\hline $\begin{array}{l}\text { Parceria com a Companhia Nacional de Abastecimento (Conab) } \\
\text { e o Programa de Aquisição de Alimentos (PAA) }\end{array}$ & Ascamade, Ascamai, ACMPJ \\
\hline $\begin{array}{l}\text { Participação do Programa Nacional de Fortalecimento da } \\
\text { Agricultura Familiar (Pronaf) mulher }\end{array}$ & ACMRBG \\
\hline Obter Declaração de Aptidão ao Pronaf (DAP) das associações & ACMRBG \\
\hline Viagens e eventos para divulgação dos produtos & Ascamade, ACMPJ \\
\hline Venda de produtos a restaurantes e turistas & ACMRBG, Ascamai, ACMRE \\
\hline
\end{tabular}

FONTE: OLIVEIRA, 2016.

Segundo os participantes da associação Ascamai, em 2014 a associação forneceu produtos da mangaba para a merenda escolar de escolas do município de Indiaroba, por meio de parceria com uma cooperativa de um assentamento rural da região. Foram fornecidos $1000 \mathrm{~kg}$ de polpa, 2000 bolinhos de mangaba e 2000 pacotes de biscoito de mangaba. As demais associações ainda não haviam fornecido merenda escolar, contudo, cientes dessa possibilidade de escoamento dos produtos, citaram essa via como uma oportunidade na cadeia produtiva da mangaba.

A ACMRBG foi a única que citou como oportunidade a participação no Programa Nacional de Fortalecimento da Agricultura Familiar (Pronaf), que se destina a estimular a geração de renda e melhorar o uso da mão de obra familiar, por meio do fornecimento de linhas de crédito para a implantação de atividades e fornecimento de serviços rurais agropecuários e não agropecuários desenvolvidos em unidades familiares ou em áreas comunitárias. Uma das linhas de crédito, o PronafMulher, é destinado especificamente a atividades desenvolvidas por mulheres, que se enquadraria no perfil das catadoras de mangaba, pois, segundo Mota et al. (2011), a prática da coleta é realizada primordialmente por mulheres.

Para participar de ambas as linhas de crédito é necessário que o extrativista ou a comunidade extrativista obtenham a Declaração de Aptidão ao Pronaf (DAP), que é um documento exigido para a concessão das linhas de crédito (BCB, 2015). Durante a oficina na ACMRBG constatou-se que, apesar das catadoras de mangaba participantes terem conhecimento de que existe o Pronaf e um documento que as habilitaria para participar do programa, estas não têm domínio do conhecimento 
sobre os meios e as adequações necessárias para conseguir essa autorização, configurando, aparentemente, uma deficiência na assistência técnica prestada pelo poder público.

A parceria com a Conab citada pelas entrevistadas dá-se pelo contexto de inserção do fruto na pauta do Política de Garantia de Preços Mínimos para os Produtos da Sociobiodiversidade (PGPMBio), que "tem o intuito de garantir a sustentação de preços mínimos também aos extrativistas" (CONAB, 2015), bem como do Programa de Aquisição de Alimentos (PAA), que é operacionalizado pela Conab e integra o Sistema Nacional de Segurança Alimentar e Nutricional (Sisan) com a finalidade de promover o acesso à alimentação e o incentivo à agricultura familiar.

O PAA é uma via importante para o escoamento da produção extrativista, tanto do fruto quanto dos produtos beneficiados, contudo, os dados disponíveis no site da Conab ${ }^{10}$ indicam que as últimas aquisições ocorreram entre os anos de 2009 e 2012, nas cidades de Estância, Indiaroba e Japaratuba (aquisição do fruto) e Santa Luzia do Itanhy (aquisição da polpa) - por isso citado como “oportunidade" pelas entrevistadas.

Um estudo de Mota et al. (2014) constatou que, em 2010, 30 catadoras de mangaba do Povoado Pontal, município de Indiaroba, já haviam formalizado sua afiliação ao PAA, e que aproximadamente 90\% tinham DAP. Contudo, segundo a Conab (2016), a participação dessas catadoras no PAA ocorreu apenas entre os anos de 2007 a 2011, e após esse período a participação foi encerrada "em decorrência de problemas burocráticos (idem, p. 5).

O conhecimento de que parcerias com a Conab, prefeituras, o PAA e o Pronaf são meios para melhorar o escoamento dos frutos da mangabeira e dos subprodutos deste demostra que as associações estão informadas a respeito de diversos mecanismos para o escoamento dos alimentos. Da mesma maneira, em nível mais local e informal, a venda de produtos a restaurantes e turistas também é reconhecida como uma via de escoamento da produção. Contudo, estas são classificadas pelas catadoras de mangaba das associações como oportunidades, isto é, ainda que algumas vezes tenham sido viabilizadas, no geral, esses meios de escoamento da produção ainda não foram consolidados, o que explica o fato de uma das fraquezas ser a falta de compradores para os produtos beneficiados (ver o tópico Fraquezas e ameaças).

Reconhecendo esse ponto, durante as oficinas duas associações destacaram a importância da divulgação dos produtos da mangaba em viagens e eventos. Durante o ano de 2016 foi possível acompanhar, na cidade de Aracaju, a divulgação dos produtos em feiras temáticas, eventos científicos, shoppings e espaços públicos, demonstrando que essa "oportunidade" tem caminhado para se tornar uma "fortaleza" se assim continuar a ser realizada.

\footnotetext{
${ }^{10} \mathrm{http}: / /$ consultaweb.conab.gov.br/consultas/consultaprecopaa.do?method=abrirConsulta
} 


\section{Fraquezas e ameaças: seleção e priorização dos pontos críticos}

Somando-se as fraquezas e ameaças citadas nas cinco oficinas, foi possível selecionar 15 problemas ou "pontos críticos" da cadeia produtiva dos frutos da mangaba no estado de Sergipe (Quadro 3), que se utilizadas pelos gestores públicos, poderão subsidiar a formulação de políticas públicas que favoreçam a sustentabilidade da cadeia produtiva da mangaba no estado de Sergipe e até mesmo fortalecer a ação territorial das catadoras de mangaba.

QUADRO3 - RESULTADO DA SOMA DA MATRIZ DE PRIORIZAÇÃO DE PROBLEMAS DAS CINCO ASSOCIAÇÕES DE CATADORAS DE MANGABA PARTICIPANTES DA PESQUISA

\begin{tabular}{|c|c|c|}
\hline Pontos críticos & $\begin{array}{l}\mathrm{N}^{\mathbf{0}} \mathrm{de} \\
\text { votos }\end{array}$ & $\begin{array}{c}\text { Priori- } \\
\text { zação }\end{array}$ \\
\hline Poucos compradores para produtos beneficiados & 18 & $1^{\mathrm{o}}$ \\
\hline Não possuir terras próprias para o extrativismo & 14 & $2^{\circ}$ \\
\hline Queimadas e desmatamento nas áreas de ocorrência natural de mangabeiras & 11 & \multirow{2}{*}{$3^{\circ}$} \\
\hline Pouco trabalho nas Unidades de Beneficiamento - UBs & 11 & \\
\hline Pouca organização/união no Movimento das Catadoras de Mangaba de Sergipe & 10 & $4^{\circ}$ \\
\hline Pouco apoio político às reinvindicações das catadoras de mangaba & 6 & $5^{\circ}$ \\
\hline Poucos cursos de capacitação/formação & 5 & \multirow{3}{*}{$6^{\circ}$} \\
\hline Construção de condomínios nas áreas de ocorrência natural de mangabeiras & 5 & \\
\hline Falta de atitude na busca por consumidores para os produtos da mangaba & 5 & \\
\hline Não existir "defeso" (auxílio durante a entressafra) para a mangaba & 4 & $7^{\circ}$ \\
\hline Falta de informação sobre novas oportunidades & 1 & \multirow{5}{*}{$8^{\circ}$} \\
\hline Não ter Declaração de Aptidão ao Pronaf (DAP) da associação & 1 & \\
\hline Pouco apoio da comunidade & 1 & \\
\hline Poucas pessoas nas associações & 1 & \\
\hline Invasão de terrenos das catadoras & 1 & \\
\hline Soma & $\mathbf{9 4}^{11}$ & - \\
\hline
\end{tabular}

FONTE: OLIVEIRA, 2016.

A seguir, os pontos críticos que receberam até a $3^{\text {a }}$ colocação na Matriz de Priorização de Problemas serão detalhados e discutidos, pois conforme explicado na metodologia, o maior número de votos recebidos indica que na visão dos extrativistas das ACMs, esses são os problemas que necessitam ser prioritariamente sanados para viabilizar o uso sustentável da mangaba no estado de Sergipe.

O problema de maior prioridade, que recebeu 18 votos, foi o fato de haver poucos compradores para os produtos beneficiados. Constatou-se que as catadoras participantes das associações conhecem políticas públicas de incentivo à comercialização da mangaba in natura, bem

\footnotetext{
11 A soma de três votos para cada um dos participantes das oficinas (33) teria como resultado "99", contudo, alguns participantes não quiseram atribuir os três votos, optando por escolher e priorizar apenas um ou dois pontos críticos.
} 
como dos produtos beneficiados (ver tópico Fortalezas e oportunidades), contudo, ainda assim o escoamento dos produtos foi considerado insatisfatório.

Durante as oficinas, por exemplo, a comunidade de Baixa Grande mostrou um freezer cheio de polpas de mangaba que, segundo as associadas, ainda não tinha nenhuma perspectiva de venda. Sobre esse tema, Figueiredo e Wadt (2000) afirmam que, dificilmente, o manejo de PFNM de base extrativista poderá competir por grandes parcelas do mercado, mas sim incluir-se na economia de nichos de mercado - que precisam ser buscados para o melhor escoamento da produção dos produtos da mangaba produzido pelas ACMs.

Ocupando a segunda posição, com 14 votos, o fato de os extrativistas não terem terras para realizar o extrativismo da mangaba foi um tema que gerou muito debate durante as oficinas. Verificou-se que há diferentes tipos de relação entre: 1) os extrativistas que não possuem terras; 2) os extrativistas que possuem terras e 3) os não extrativistas que possuem terras.

Em todas as associações pesquisadas existem os dois tipos de extrativistas e a relação entre eles se dá da seguinte maneira: há respeito pela delimitação das terras ou não. Isto é, no primeiro caso, há comunidades em que a maioria dos extrativistas possui terras com a presença de mangabeiras e, portanto, cada um relatou coletar apenas em suas próprias terras (a comunidade de Baixa Grande - Pirambu, por exemplo, relatou esse caso); contudo, há comunidades em que a maioria dos extrativistas não possui terras e houve relatos por parte dos extrativistas que possuem terras de que, quando vão coletar os frutos, encontram cercas rompidas, galhos quebrados e frutos verdes no chão - consequências da ação de "furto" dos frutos por parte de outros extrativistas (as comunidades de Pontal - Indiaroba e Porteiras - Japaratuba relataram essa relação). Em Manoel Dias - Itaporanga D’Ajuda e Riboleirinha - Estância, ocorrem ambas relações entre os extrativistas que possuem ou não acesso à terra.

Por sua vez, a relação com os não extrativistas que possuem terras ou é indiferente, quando as catadoras não têm conhecimento de quem é o dono das terras e nunca tiveram proibição para coletar nessas áreas, se referindo às terras como "área livre" (citado pela comunidade de Porteiras Japaratuba), ou é positiva ou negativa. Nas relações positivas, os não-extrativistas donos da terra consentem no acesso gratuito a quaisquer catadoras de mangaba (caso relatado pelas catadoras de Pontal - Indiaroba), ou consentem no extrativismo realizado pela família de catadoras de mangaba que é responsável pelo cuidado das terras (referem-se a si mesmos como "vigias/caseiros", caso relatado em Pontal, Riboleirinha e Manoel Dias) ou, ainda, consentem no extrativismo mediante pagamento, que pode ser feito de duas formas: "arrendamento" - aluguel mensal ou por safra para coleta livre de frutos (caso relatado em Baixa Grande) - ou compra das quantidades de frutos que foram extraídos (caso relatado em Porteiras). 
Sobre esse assunto, Pereira et al. (2009) identificaram que dos 38.921 hectares indicados pelos extrativistas como áreas de coleta do fruto da mangaba em Sergipe no ano de 2009, apenas $16 \%$ eram áreas pertencentes a extrativistas; identificaram ainda que em $49 \%$ dessa área é permitida a coleta dos frutos, em $12 \%$ é proibida a entrada e em $17 \%$ a zona é conflituosa.

Como o acesso às áreas de ocorrência natural das mangabas é essencial à prática extrativista, entende-se que a existência de áreas inacessíveis prejudica a sustentabilidade da cadeia produtiva da mangaba no estado de Sergipe, fato já reconhecido para outra espécie explorada de forma extrativista em território brasileiro: o babaçu, cuja luta por parte do Movimento Interestadual das Quebradeiras de Coco-Babaçu (MIQCB) culminou na criação de leis do "Babaçu Livre", promulgadas em alguns municípios dos estados do Piauí, Maranhão, Tocantins e Pará, com o fim de garantir a reprodução das práticas socioculturais ligadas ao extrativismo da espécie através do livre acesso às áreas de ocorrência natural, ainda que estas se encontrem em terras privadas (NETO, 2012).

Contudo, há uma diferença entre os babaçuais e as mangabeiras em terras privadas: em geral, os babaçuais não são cultivados, enquanto as mangabeiras já são cultivadas em algumas áreas do estado de Sergipe (EMDAGRO, 2009), e apesar desse cultivo ocorrer em áreas ainda restritas, apenas o fato de existir traz mais entraves à instituição de leis como a do "Babaçu Livre", pois como é possível diferenciar os espécimes de ocorrência natural, as quais as catadoras afirmam possuir direitos sobre elas, dos cultivados?

Desse modo, o ponto crítico relativo à diminuição das terras disponíveis para o extrativismo da mangaba por parte das catadoras de mangaba precisa ser melhor discutido, visto que o cercamento das áreas anteriormente de livre acesso aos extrativistas tem limitado a atividade, reconhecidamente tradicional, e ferido a legislação estadual que reconhece as catadoras de mangaba como grupo culturalmente diferenciado e garante, dentre outros, a proteção dos territórios por elas reivindicados e explorados.

Ocupando a terceira posição, com 11 votos, estão a carência de trabalho nas Unidades de Beneficiamento (UBs), bem como a ocorrência de queimadas e desmatamentos. A carência de trabalho nas UBs está diretamente relacionada à baixa quantidade de compradores para os produtos, afinal, só há trabalho se houver demanda pelos subprodutos do fruto da mangabeira. Com isso, os participantes da oficina relataram que necessitam complementar a renda com outras atividades, bem como que há evasão dos associados que, desestimulados com a baixa procura dos produtos beneficiados, optam por voltar a vender apenas o fruto in natura.

A preocupação com a ocorrência de queimadas e desmatamentos nas áreas naturais de ocorrência da mangabeira refletem o estado atual de conservação das áreas remanescentes de mangabeiras, que têm sido paulatinamente substituídas por outros usos do solo. Para Lederman e 
Bezerra (2006, p. 248), "a ameaça de desaparecimento da mangabeira, principalmente nos tabuleiros costeiros e baixada litorânea do Nordeste, é uma realidade", pois todo o litoral nordestino vem passando por uma intensiva ocupação urbana e, além disso, a mangabeira sofre uma concorrência intensiva com o cultivo da cana-de-açúcar, que se expandiu das regiões de Zona da Mata para os solos dos tabuleiros costeiros da região.

Essa substituição das áreas naturais de ocorrência das mangabeiras ocorreu principalmente nos estados de Alagoas, Pernambuco, Paraíba e Rio Grande do Norte (LEDERMAN; BEZERRA, 2006). Em Sergipe, as áreas remanescentes permaneceram mais conservadas em relação aos demais estados nordestinos, provavelmente, devido à ocupação tardia do litoral sergipano com atividades de cunho turístico (SILVA JÚNIOR et al., 2011). Contudo, para os autores, a modificação dessa realidade nas últimas décadas tem despertado a preocupação das comunidades da região para a proteção da vegetação natural, inclusive, estimulando o plantio de mangabeiras pelos donos de terras, catadores ou não, e a proibição de cortes de árvores e do extrativismo predatório.

\section{Considerações finais}

O uso de ferramentas do Diagnóstico Rural Participativo foi eficaz para selecionar os pontos críticos do sistema extrativista da mangaba a partir da visão dos participantes das associações de catadoras de mangaba. Ressalta-se que abordagens como a deste manuscrito, em que os atores sociais são ouvidos desde as fases iniciais do planejamento - descrição dos sistemas e o apontamento das fortalezas e fragilidades encontrados - são essenciais para a construção de um planejamento ambiental adequado à realidade local, fugindo de generalizações e extrapolações que por diversas vezes tornam-se ineficazes para a gestão sustentável dos recursos naturais.

Os pontos críticos apontados pelos extrativistas subsidiarão a seleção de indicadores de sustentabilidade para a cadeia produtiva dos frutos da mangaba no estado de Sergipe. O uso de desses indicadores, aliados a outros, que vem sendo construído em conjunto com os diferentes atores sociais envolvidos na cadeia produtiva, poderá permitir o monitoramento da atividade a fim de, primeiramente, constatar o atual estado da sustentabilidade do extrativismo e da cadeia produtiva da mangaba no estado e, por seguinte, conduzir a ações que permitam a superação dos desafios que dificultam a manutenção de uma sustentabilidade social, econômica e ambiental.

Ainda com base nos pontos críticos apontados, é imperativo que políticas públicas que envolvam a conservação da mangabeira sejam construídas em parceria com a sociedade, garantindo adequação à realidade dos diferentes atores sociais envolvidos na cadeia produtiva do fruto, incluindo 
as catadoras de mangaba. Essas políticas devem atender e enquadrar-se à uma realidade territorial, englobando os demais produtos extrativos explorados no estado de Sergipe e região, com o intuito de contribuir para o uso sustentável e a valorização da sociobiodiversidade visando ao desenvolvimento regional.

\section{Referências}

AEM. Avaliação Ecossistêmica do Milênio, 2005. Ecossistemas e bem-estar humano: oportunidades e desafios para as empresas e a indústria. Instituto de Recursos Mundiais (WRI), Washington, EUA. Edição em Português - março de 2006.

ALlEGRETTI, M. H. Usar para valorizar. Revista de História da Biblioteca Nacional, Rio de Janeiro, ano 4, n. 44, p. 22-25, 2009.

ALMEIDA, M. W. B. de; Direitos à floresta e ambientalismo: os seringueiros e suas lutas. Revista Brasileira de Ciências Sociais, v. 19, n. 55, p. 35-52, 2004.

BENATTI, J. H. Populações tradicionais e o manejo dos recursos naturais renováveis no Parque Nacional do Jaú: uma análise jurídica. In: Reunião Brasileira de Antropologia. Fórum de Pesquisa 3 - Conflitos socioambientais e Unidades de Conservação. Brasília, 2000.

BCB. Banco Central do Brasil. FAQ - Programa Nacional de Fortalecimento da Agricultura Familiar. - Pronaf. Julho de 2015.20 Disponível em: <https://www.bcb.gov.br/pre/bc_atende/port/PRONAF.asp>. Acesso em: 07 maio 2017.

BRASIL. Lei 9.985, de 18 de julho de 2000. Regulamenta o art. 225, $\S 1^{\circ}$, incisos I, II, III e VII da Constituição Federal, institui o Sistema Nacional de Unidades de Conservação da Natureza e dá outras providências. Disponível em: <http://www.planalto.gov.br/ccivil_03/leis/L9985.htm>. Acesso em: 07 maio 2017.

BRASIL. Decreto 6.040, de 7 de fevereiro de 2007. Institui a Política Nacional de Desenvolvimento Sustentável dos Povos e Comunidades Tradicionais. Disponível em: <http://www.planalto.gov.br/ccivil_03/_ato2007-2010/2007/decreto/d6040.htm>. Acesso em: 07 maio 2017.

BRASIL. Ministério do Meio Ambiente. Panorama da biodiversidade Global 3. Brasília: MMA, 2010.

BRITO, F. Corredores ecológicos: uma estratégia integradora na gestão de ecossistemas. Florianópolis: UFSC, 2006.

CAVALCANTE, K. V.; LOPES, R. H.; FRANCHI, T.; MOTA, J. A. O extrativismo no século XXI: a castanha no Amazonas. In: IX Encontro da Sociedade Brasileira de Economia Ecológica, Brasília, 2011. 
CONAB. Companhia Nacional de Abastecimento. Proposta de preços mínimos 2015/2016, Brasília, v. 2, mar. 2015.

CONAB. Companhia Nacional de Abastecimento. Conjuntura Mangaba: julho de 2016. Disponível em: <http://www.conab.gov.br/OlalaCMS/uploads/arquivos/16_08_15_16_03_20_07_-_jul__2016_-_conjuntura_mangaba.pdf >. Acesso em: 07 maio 2017.

EMDAGRO. Empresa de Desenvolvimento Agropecuário de Sergipe. Notícia no portal. Cultivo comercial da mangaba pode mudar vida de produtores. Publicado em: 13/05/2009. Disponível em: <http://www.emdagro.se.gov.br/modules/news/article.php?storyid=150>. Acesso em: 19 ago. 2015.

FAO. Organização das Nações Unidas para a Agricultura e Alimentação. Indicadores de resultado e impacto en el território. Disponível em: <http://www.fao.org/in-action/territoriosinteligentes/componentes/sostenibilidad-sistemica/indicadores-de-resultado/es/>. Acesso em: 07 maio 2017.

FIGUEIREDO, E. O.; WADT, L. J. de O. Aspectos fundamentais para o manejo de produtos não madeireiros. Comunicado Técnico nº109, Embrapa Acre, julho de 2000.

FOLHA DE SÃO PAULO. Mangaba pode ser plantada em pomares. São Paulo, 24 de janeiro de 1995. Disponível em: <http://www1.folha.uol.com.br/fsp/1995/1/24/agrofolha/9.html\#_=_>. Acesso em: 19 ago. 2015.

GOMES, R. P. Fruticultura brasileira. 13. ed. São Paulo: Nobel, 2012.

GOMES, L. J.; GOMES, M. A. O; JESUS, N. B. de. Aspectos socioambientais da atividade extrativista de produtos florestais não madeireiros: os casos da Fava-D'Anta (Dimorphandra sp.) e da Aroeira-da-praia (Schinus terebinthifolius Raddi). In: ALBUQUERQUE, U. P. de; HANAZAKI, N. (Orgs.). Árvores de valor e o valor das árvores: pontos de conexão. Recife: Nupeea, 2010.

GOMES, L. J.; SILVA-MANN, R. Indicadores de sustentabilidade. In: Pensando a biodiversidade: aroeira (Schinus terebinthifolius Raddi.). São Cristóvão: UFS, 2013.

GUIMARÃES, R. P.; FEICHAS, S. A. Q. Desafios na construção de indicadores de sustentabilidade. Ambiente \& Sociedade, Campinas, v. 12, n. 2, p. 307-323, jul.-dez. 2009.

HOMMA, A. K. O. Uma tentativa de interpretação teórica do extrativismo amazônico. Acta Amazonica, Manaus, v. 12, n. 2, p. 251-255, 1982.

Extrativismo, manejo e conservação dos recursos naturais na Amazônia In: MAY, P. H. (Org.). Economia do meio ambiente: teoria e prática. Rio de Janeiro: Campus Elsevier, 2010.

. Extrativismo vegetal ou plantio: qual a opção para a Amazônia? Estudos Avançados, v. 26 n. 74, p. 167-186, 2012.

IBGE. Instituto Brasileiro de Geografia e Estatística. Produção da extração vegetal e silvicultura 2014. Rio de Janeiro: IBGE, 2014. (v. 29). 
JESUS, J. B. de; GAMA, D. C.; FERNANDES, M. M. Estudo da distribuição do bioma Mata Atlântica no estado de Sergipe. In: VIII SIMPÓSIO BRASILEIRO DE PÓS-GRADUAÇÃO EM CIÊNCIAS FLORESTAIS. Anais... Recife - PE, 2014.

$\mathrm{KOCH}$, I. et al. Apocynaceae in lista de espécies da flora do Brasil. Jardim Botânico do Rio de Janeiro. Disponível em: <http://floradobrasil.jbrj.gov.br/jabot/floradobrasil/FB15558>. Acesso em: 03 maio 2015.

LEDERMANN, I. E.; BEZERRA, J. E. F. Situação atual e perspectivas da cultura. In: SILVA JÚNIOR; J. F. da; LÉDO, A. da S. A cultura da mangaba. Aracaju: Embrapa Tabuleiros Costeiros, 2006.

LEIVA, F. A.; FREITAS, R. R. de. Populações tradicionais e conservação da biodiversidade uma relação contratual para manutenção dos territórios. In: $7^{\circ}$ CONGRESO CHILENO DE ANTROPOLOGIA. São Pedro de Atacama, out. 2010. Disponível em: <http://www.nepam.unicamp.br/cgcommons/download/2_Populacaoes_Tradicionais_e_Conservaca o_da_Biodiversidade.pdf >. Acesso em: 07 maio 2017.

LIMA, I. L. P. Boas práticas de manejo para o extrativismo sustentável da mangaba. Brasília: Embrapa Recursos Genéticos e Biotecnologia, 2010.

LOPEZ-RIDAURA, S.; MASERA, O.; ASTIER, M. Evaluating the sustainability of complex socioenvironmental systems. The MESMIS framework. Ecological Indicators, v. 2, p.135-148, 2002.

MARCONI, M. A.; LAKATOS, E. M. Técnicas de pesquisa: planejamento e execução de pesquisas, amostragens e técnicas de pesquisa, elaboração, análise e interpretação de dados. 3. ed. São Paulo: Atlas, 1996.

MAROTTI, J. et al. Amostragem em pesquisa clínica: tamanho da amostra. Revista de Odontologia da Universidade Cidade de São Paulo, v. 20, n. 2, p. 186-194, 2008.

MASERA, O. et al. El proyecto de evaluación de sustentabilidade MESMIS. In: ASTIER, M.; MASERA, O. R; GALVÁN-MIYOSHI, Y. (Coords.). Evaluación de sustentabilidad: un enfoque dinámico y multidimensional. España: SEAE, CIGA, CIECO, ECOSUR, GIRA, FIAES, Mundiprensa, 2008.

MAY, P. Building institutions and markets for non-wood forest products from the Brazilian Amazon. Unasylva, v. 165, n. 42, p. 9-16, 1991.

MOTA, D. M. da et al. As senhoras da mangaba. In: MOTA, D. M. da et al. A mangabeira, as catadoras, o extrativismo. Belém: Embrapa Amazônia Oriental; Aracaju: Embrapa Tabuleiros Costeiros, 2011.

MOTA, D. M. da et al. As catadoras de mangaba no Programa de Aquisição de Alimentos - PAA: um estudo de caso em Sergipe. Rev. Econ. Sociol. Rural, Brasília, v. 52, n. 3, p. 449-470, set. 2014.

MOURA, N. F. et al. Diversidade genética e variação fenotípica de caracteres morfológicos em mangaba (Hancornia speciosa Gomes). In: IX SIMPÓSIO NACIONAL CERRADO. II SIMPÓSIO INTERNACIONAL SAVANAS TROPICAIS. Brasília: ParlaMundi, 2008. 
MPMG. Ministério Público de Minas Gerais. Coordenadoria de Inclusão e Mobilização Sociais. Direitos dos povos e comunidades tradicionais. 2014. Disponível em: 〈https://goo.gl/sWma4p〉. Acesso em: 07 maio 2017.

NETO, N. M. da S. A lei do babaçu livre: usos e representações jurídicas das quebradeiras de coco babaçu. Perspectiva Amazônica, Santarém, ano II, v. 3, p. 7-18, jan. 2012.

PEREIRA, E. O. et al. Mapa do extrativismo da mangaba em Sergipe: ameaças e demandas. Aracaju: Embrapa Tabuleiros Costeiros, 2009.

Mapa do extrativismo da mangaba em Sergipe: ameaças e demandas. Dados vetoriais do geoprocessamento. Aracaju: Embrapa Tabuleiros Costeiros, 2010.

POSEY, D. A. Etnobiologia: teoria e prática. In: RIBEIRO, B. (Ed.). Suma etnobiológica brasileira - 1 Etnobiologia. Petrópolis, Vozes/Finep, 1987.

SANTOS, R. F. Planejamento ambiental: teoria e prática. São Paulo: Oficina dos Textos, 2004.

SCHMITZ, H. et al. Conflitos e movimento social: ameaças e reações das catadoras de mangaba. In: MOTA, D. M. da et al. A mangabeira as catadoras o extrativismo. Belém: Embrapa Amazônia Oriental; Aracaju: Embrapa Tabuleiros Costeiros, 2011.

SERGIPE. Decreto n⿳ 12.723, de 20 de janeiro de 1992. Institui a mangabeira como árvore símbolo do estado de Sergipe e dá providências correlatas. Disponível em: <https://goo.gl/Dm1k5A $>$. Acesso em: 11 set. 2015.

SERGIPE. Lei $\mathbf{n}^{\mathbf{0}} \mathbf{7 . 0 8 2}$, de 16 de dezembro de 2010. Reconhece as catadoras de mangaba como grupo cultural diferenciado e estabelece o autorreconhecimento como critério do direito e dá outras providências. Disponível em: <https://goo.gl/vqsH4K〉. Acesso em: 11 set. 2015.

SILVA, C. V. da.; MIGUEL, L. de A. Extrativismo e abordagem sistêmica. Novos Cadernos NAEA, v. 17, n. 2, p. 189-217, dez. 2014.

SILVA JUNIOR, J. F. da; MOTA, D. M. da; SCHMITZ, H. No rastro da mangabeira. In: MOTA, D. M. da et al. A mangabeira, as catadoras o extrativismo. Belém: Embrapa Amazônia Oriental; Aracaju: Embrapa Tabuleiros Costeiros, 2011.

SILVA JUNIOR, J. F. da et al. "Rainha dos Tabuleiros": a mangabeira em Sergipe. In: MOTA, D. M. da et al. A mangabeira, as catadoras o extrativismo. Belém: Embrapa Amazônia Oriental; Aracaju: Embrapa Tabuleiros Costeiros, 2011.

SOLDATI, G. T.; ALBUQUERQUE, U. P. de; Produtos florestais não madeireiros: uma visão geral. In: ALBUQUERQUE, U. P. de; HANAZAKI, N. (Orgs.). Árvores de valor e o valor de uso das árvores: pontos de conexão. Recife: Nupeea, 2010.

VALVERDE, S. R. et al. Silvicultura brasileira - Oportunidades e desafios da economia verde. Fundação Brasileira para o Desenvolvimento Sustentável. Disponível em: <http://fbds.org.br/fbds/IMG/pdf/doc-549.pdf>. Acesso em: 31 mar 2014.

VAN BELLEN, H. M. Indicadores de sustentabilidade: uma análise comparativa. Rio de Janeiro: FGV, 2005. 
VERDEJO, M. E. Diagnóstico Rural Participativo - DRP: um guia prático. Brasília: Secretaria da Agricultura Familiar; Ministério do Desenvolvimento Agrário, 2006.

Recebido em 16/04/2017. Aceito para publicação em 03/07/2017. 